\title{
Protective Effects of Genistein against Mono-(2-ethylhexyl) Phthalate-Induced Oxidative Damage in Prepubertal Sertoli Cells
}

\author{
Liandong Zhang, ${ }^{1}$ Ming Gao, ${ }^{2}$ Tongdian Zhang, ${ }^{1}$ Tie Chong, ${ }^{1}$ Ziming Wang, \\ Xiaoqiang Zhai, ${ }^{1}$ Zhizhong $\mathrm{Wu}^{1}{ }^{1}$ and Hecheng $\mathrm{Li}^{1}$ \\ ${ }^{1}$ Department of Urology, The Second Affiliated Hospital, Xian Jiaotong University, Xian, Shaanxi 710004, China \\ ${ }^{2}$ Department of Nephrology, Xian No. 4 Hospital, Xian, Shaanxi 710004, China
}

Correspondence should be addressed to Ziming Wang; ziming-w@263.net

Received 2 May 2017; Revised 13 August 2017; Accepted 21 August 2017; Published 13 November 2017

Academic Editor: Ferdinando Chiaradonna

Copyright ( 2017 Liandong Zhang et al. This is an open access article distributed under the Creative Commons Attribution License, which permits unrestricted use, distribution, and reproduction in any medium, provided the original work is properly cited.

\begin{abstract}
Mono-(2-ethylhexyl) phthalate (MEHP) and genistein are two of the most prevalent endocrine-disrupting chemicals (EDCs) that present in the environment and food. However, how these two EDCs would affect prepubertal Sertoli cells development was rarely studied. In this study, primary prepubertal Sertoli cells were isolated from 22-day-old Sprague Dawley rats and exposed to MEHP at $1 \mu \mathrm{mol} / \mathrm{L}, 10 \mu \mathrm{mol} / \mathrm{L}$, and $100 \mu \mathrm{mol} / \mathrm{L}$ (M1, M10, and M100), genistein at $10 \mu \mathrm{mol} / \mathrm{L}$ (G), and their combination $(\mathrm{G}+\mathrm{M} 1, \mathrm{G}+\mathrm{M} 10$, and $\mathrm{G}+\mathrm{M} 100)$. Cell proliferation inhibition rate, apoptosis and necrosis rate, and cellular redox state were evaluated. Our results revealed that MEHP could significantly increase cell proliferation inhibition rate, apoptosis rate, necrosis rate, and intracellular reactive oxidative species level. However, coadministration of genistein could partially alleviate MEHP-induced prepubertal Sertoli cells oxidative injuries via enhancement of testicular antioxidative enzymes activities and upregulation of Nrf2 and HO-1, indicating that genistein could partially attenuate MEHP-induced prepubertal Sertoli cells damage through antioxidative action and may have promising future on its curative role for attenuating other EDCs-induced reproductive disorders.
\end{abstract}

\section{Introduction}

It is widely acknowledged that endocrine-disrupting chemicals (EDCs) may interfere with the body's endocrine system and produce adverse developmental, reproductive, neurological, and immune effects in both humans and wildlife [1]. Multiple studies revealed that exposure to EDCs including bisphenol $\mathrm{A}$ and beta-cypermethrin was closely related to male reproductive system impairment $[2,3]$, particularly if exposure occurred during early development [4].

From the time of conception through adulthood, humans are exposed to countless anthropogenic and naturally occurring EDCs. Among them, genistein and mono (2-ethylhexyl) phthalate (MEHP) are two kinds of the most prevalent EDCs found in food and environment. Genistein and daidzein, two major soy isoflavone glucosides, are present at high concentrations in soybeans and soybean-derived products and are major sources of xenooestrogen exposure in both humans and animals. Previous studies revealed isoflavones could mimic the actions of oestrogens and clinical reports did not find any adverse effects on male reproductive physiology [5]. More recently, the antioxidative role of genistein aroused great concern [6]. It is interesting to note that genistein could enhance fertility by promoting acrosome reaction at lower doses but potentially suppress male fertility via suppressing acrosome reaction at higher doses [7]. Isoflavones including genistein were also reported to modulate activity of antioxidative defence system and alleviate the oxidative stress induced by the other EDCs cadmium, TPA $[8,9]$.

MEHP is the metabolite of the widely used plasticizer di(2-ethylhexyl) phthalate (DEHP); Culty et al. [10] revealed that DEHP and MEHP exerted their antiandrogen effect by suppressing fetal testosterone biosynthesis via peroxisome proliferator-activated receptors (PPARs) activation; Sobarzo 
et al. [11] found that MEHP induced oxidative stress in prepubertal Sertoli cells through regulating the level of lipoperoxides, glutathione, and glutathione S-transferases (GST). Epidemiological study also showed that urinary oxidative stress marker malondialdehyde (MDA) concentration was closely associated with levels of several DEHP metabolites in prepubertal children, providing evidence of the association between phthalate exposure and oxidative stress among the early teenagers [12].

Previous studies mainly focused on the reproductive outcome after single EDC exposure; however, the fact that categories of various EDCs are in large amounts in the environment makes it urgent to make it clear how EDCs mixtures would affect reproductive system, especially for those acting via different mechanisms. Our most recent study demonstrated that genistein could normalize DEHP induced neonatal effects through antioxidative action, which also revealed coadministration of the two EDCs did not follow classical dose-response effects and highlighted the importance of assessing impacts across a range of doses and ages [13]. Compared to neonatal testis, prepubertal testis was classically described as quiescent while Sertoli cells were the most active testicular cell population as testis size increase during prepuberty was mainly due to Sertoli cells proliferation [14]. The nursing role of Sertoli cells ensures import and export of nutrients, hormones, and other chemicals into the tubules, and in this sense Sertoli cells should be the frontline exposed to EDCs and how EDCs would affect Sertoli cells would have fundamental implication on spermatogenesis. The effects of combined exposure to genistein and MEHP on prepubertal Sertoli cells still need further investigation.

Oxidative stress is a common pathological process involved in the process of EDCs-induced testicular cell injury, which makes it possible to have oxidative stress monitoring as an informative way to study interactions between numerous toxicants and the reproductive consequences [15]. We hypothesized that low dose of genistein exposure would exert its antioxidative role in prepubertal Sertoli cells, which may partially alleviate the toxic effects induced by different doses of MEHP. Herein we examined the parameters including Sertoli cells proliferation, apoptosis and intracellular reactive oxygen species (ROS) level, expression of genes and proteins related to antioxidation and apoptosis, and enzymes involved in the regulation of testicular redox state, hoping to gain insight into the early cellular and molecular events that may drive long-term changes.

\section{Materials and Methods}

2.1. Sertoli Cells Isolation, Culture, and Treatment. 22-dayold Sprague Dawley rats were used as donors in order to obtain the prepubertal Sertoli cells. Prior to study initiation, the experimental protocol was reviewed and approved by the Committee on Animal Research and Ethics of Xian Jiaotong University (Xian, China). 22-day-old specific pathogen-free (SPF) Sprague Dawley rats were obtained after weaning from the Experimental Animal Center of Xian Jiaotong University.
A two-step enzymatic digestion protocol was used to obtain testicular single-cell suspensions enriched for Sertoli cells [16]. Rat testes were removed, decapsulated, and rinsed twice in sterile phosphate-buffered saline (PBS). After being minced, the testes fragments were digested using $0.25 \%$ trypsin (TransGen Biotech, Beijing, China) at $37^{\circ} \mathrm{C}$ in a rocking incubator for $30 \mathrm{~min}$, and then Dulbecco's Minimum Essential Medium (DMEM, $4.5 \mathrm{~g}$ glucose/ml) mixed $1: 1$ with Ham's F12 (DMEM-F12) medium containing 10\% fetal bovine serum (FBS), penicillin $(100 \mathrm{IU} / \mathrm{ml})$, and streptomycin (100 IU/ml) (TransGen Biotech, Beijing, China) was added to terminate the first-step digestion and centrifuged twice at $1500 \mathrm{rpm}$. In the second step of digestion, $2 \mathrm{ml}$ $0.05 \%$ type V collagenase (Sigma-Aldrich Inc., St. Louis, USA) was added to the isolated tubular fragments and further digested at $37^{\circ} \mathrm{C}$ in a rocking incubator for $30 \mathrm{~min}$. After that, the isolated cell suspension was filtered through a 200mesh stainless steel filter and centrifuged twice at $1500 \mathrm{rpm}$ for $5 \mathrm{~min}$. Cells were then resuspended using DMEM-F12 medium containing $10 \% \mathrm{FBS}$, penicillin $(100 \mathrm{IU} / \mathrm{ml})$, and streptomycin $(100 \mathrm{IU} / \mathrm{ml})$. Finally, dispersed cells were seeded on cell culture flask at the density of $1.5 \times 10^{6}$ cells $/ \mathrm{ml}$ and were incubated under the condition of $37^{\circ} \mathrm{C}$ and $5 \% \mathrm{CO}_{2}$. After being cultured for 2 days, Sertoli cells attached to the bottom of flask with tiny dendrites protruding while the germ cells floated in the medium and can be removed after changing the medium.

Further identification and purity of Sertoli cells were assessed by immunocytochemistry (IHC) labeled with antifollicle-stimulating hormone receptor (anti-FSHR) antibody (Bioss Biology Corporation, Beijing, China). The cells were plated onto poly-L-lysine-coated cover slips for $20 \mathrm{~min}$ and $4 \%$ paraformaldehyde fixed for $15 \mathrm{~min}$. After washing with 1x PBS for 3 times, the cells were incubated with 5\% bovine serum albumin (BSA) and incubated with FSHR antibody $(1: 200)$ overnight at $4^{\circ} \mathrm{C}$. On the second day, the slides were washed 3 times with $1 x$ PBS and were then incubated with Biotin-Labeled Goat Anti-Rabbit IgG (Boster, Wuhan, China) at $37^{\circ} \mathrm{C}$ for $1 \mathrm{~h}$. After being incubated with streptavidin-biotin complex (SABC, Boster, Wuhan, China) for 20 mins, the positive cells were visualized using the DAB kit (Boster, Wuhan, China).

MEHP (CAS: 4376-20-9, obtained from Accustandard Inc., Connecticut, USA) and genistein (CAS: 446-72-0, obtained from Sigma-Aldrich Inc., St. Louis, USA) were dissolved in $99.5 \%$ pure dimethylsulfoxide (DMSO, CAS: 67-68-5, obtained from Sigma-Aldrich Inc., St. Louis, USA) into stock solutions of $100 \mathrm{mM}$. After being reseeded for $24 \mathrm{~h}$, Sertoli cells were exposed to vehicle (Control), GEN $(10 \mu \mathrm{mol} / \mathrm{L}, \mathrm{G}), \operatorname{MEHP}(1,10$, and $100 \mu \mathrm{mol} / \mathrm{L} ; \mathrm{M} 1, \mathrm{M} 10$, $\mathrm{M} 100)$, or GEN + MEHP $(10 \mu \mathrm{mol} / \mathrm{L}+1 \mu \mathrm{mol} / \mathrm{L}, 10 \mu \mathrm{mol} / \mathrm{L}$ $+10 \mu \mathrm{mol} / \mathrm{L}$, and $10 \mu \mathrm{mol} / \mathrm{L}+100 \mu \mathrm{mol} / \mathrm{L} ; \mathrm{G}+\mathrm{M} 1, \mathrm{G}+\mathrm{M} 10$, and $G+M 100)$ separately. The range of MEHP doses was based on the No Observable Adverse Effect Level (NOAEL) of MEHP for human testicular cells, ranging between $1 \mu \mathrm{mol} / \mathrm{L}$ and $10 \mu \mathrm{mol} / \mathrm{L}$ [17], and we also included the dose higher than NOAEL. The dose of genistein in this research was based on the serum genistein concentration in the soy formula-fed infants, which ranges from $1 \mu \mathrm{mol} / \mathrm{L}$ to $10 \mu \mathrm{mol} / \mathrm{L}$ [18]. 
2.2. MTT Assay to Detect Cell Proliferation Inhibition Rate. Purified Sertoli cells were trypsinized and reseeded in 96-well culture plates. Following adhesion, cells were exposed to GEN $(10 \mu \mathrm{mol} / \mathrm{L})$ and different concentrations of MEHP $(1,10$, and $100 \mu \mathrm{mol} / \mathrm{L})$, or GEN + MEHP $(10 \mu \mathrm{mol} / \mathrm{L}+1 \mu \mathrm{mol} / \mathrm{L}$, $10 \mu \mathrm{mol} / \mathrm{L}+10 \mu \mathrm{mol} / \mathrm{L}$, and $10 \mu \mathrm{mol} / \mathrm{L}+100 \mu \mathrm{mol} / \mathrm{L})$ for 24 or $48 \mathrm{~h}$. The control group was treated with solvent only. After incubation, $20 \mu \mathrm{l}$ of $5 \mathrm{mg} / \mathrm{ml}$ MTT (Sigma-Aldrich Inc., St. Louis, USA) was added to each well and the cells were further incubated for $4 \mathrm{~h}$. After removing the media, $150 \mu \mathrm{l}$ MTT solvent was added. The absorbance was measured on an automated microplate reader (Thermo Fisher Scientific, USA) at $490 \mathrm{~nm}$ after agitating cells on orbital shaker for $10 \mathrm{~min}$, and $A$ value was recorded. The cell proliferation inhibition rate was calculated as follows: $1-A$ (treatment) $/ A$ (control) $\times 100 \%$.

2.3. Flow Cytometry Assay. Following treatment with chemicals for $48 \mathrm{~h}$, Sertoli cells were trypsinized using $0.25 \%$ trypsin containing no EDTA (TransGen Biotech, Beijing, China), harvested at $2000 \mathrm{rpm}$ for $5 \mathrm{~min}$, washed twice with cold PBS, and resuspended in $500 \mu \mathrm{L}$ binding buffer at the concentration of $6 \times 10^{5}$ cells $/ \mathrm{ml}$. Next, cells were stained with $1 \mu \mathrm{g} / \mathrm{ml}$ Annexin V-APC and $1 \mu \mathrm{g} / \mathrm{ml}$ 7-AAD (TransGen Biotech, Beijing, China) in the dark for $10 \mathrm{~min}$ and analyzed using a Flow Cytometer System (Beckman Coulter, Miami, USA).

2.4. ROS Assay. After being treated with chemicals for $48 \mathrm{~h}$ on 24-well plate, Sertoli cells were incubated with carboxy$2^{\prime}, 7^{\prime}$-dichloro-dihydro-fluorescein diacetate (DCFH-DA) (Sigma-Aldrich Inc., St. Louis, USA) probe dissolved in DMEM/F12 medium at the concentration of $10 \mu \mathrm{M}$ at $37^{\circ} \mathrm{C}$ for $30 \mathrm{~min}$ and then washed by DMEM/F12 medium for $5 \mathrm{~min}, 3$ times. Fluorescence was observed and pictures were taken under the fluorescence microscope (Olympus, Tokyo, Japan) at $488 \mathrm{~nm}$ (excitation) and $525 \mathrm{~nm}$ (emission) wavelengths. Integral optical density value (IOD) was measured using Image-Pro Plus 5.0 (Media Cybernetics, Bethesda, USA).

All assays were performed in at least three individual experiments, each comprising no less than three replicates.

2.5. Evaluation of Medium Redox State. After Sertoli cells were treated with chemicals for $48 \mathrm{~h}$, medium was collected for further redox state analysis. Total antioxidant capacity (TAOC), superoxide dismutase (SOD), total GSH, glutathione disulfide (GSSG), and thiobarbituric acid reactive substances (TBARS) were evaluated using the clinical chemistry assay kits (Nanjing Jiancheng Bioengineering Institute, China) according to the manufacturer's instruction to monitor testicular redox state.

T-AOC was determined by the ferric reducing/antioxidant power assay and detected at $520 \mathrm{~nm}$ using the spectrophotometer, the final concentration was expressed as $\mathrm{U} / \mathrm{ml}$.

SOD activity was measured by water soluble tetrazolium salts assay (WST-1), which monitored the inhibition rate of SOD to the process of formazan dye formation from tetrazolium salt mediated by the superoxide anion. The absorbance was scanned at $450 \mathrm{~nm}$ using a microplate reader. The final result was expressed as $\mathrm{U} / \mathrm{ml}$.

T-GSH and GSSG content were measured using dithionitrobenzoic acid reagent and the absorbance was scanned at $405 \mathrm{~nm}$ using microplate reader, GSH content was calculated as T-GSH-2 $\times$ GSSG, and the final results were expressed as the ratio of GSH/GSSH.

TBARS was measured and the absorbance was measured with the ultraviolet spectrometer at $532 \mathrm{~nm}$ against blanks prepared by distilled water, results were expressed as $\mathrm{nmol} / \mathrm{ml}$.

2.6. RNA Extraction and Quantitative Real-Time PCR. Sertoli cells RNA was extracted using total RNA extraction kit (Fastagen, China). cDNA was synthesized from isolated RNA using RevertAid ${ }^{\mathrm{TM}}$ First-Strand cDNA Synthesis Kit (Thermo Fisher Scientific, USA). Quantitative real-time PCR (qPCR) was performed using the Bio-Rad Real-Time PCR System (IQ5, Bio-Rad). Beta-actin was used as an endogenous control and for normalization of gene targets. The relative gene expression was analyzed using the $2^{-\Delta \Delta \mathrm{Ct}}$ algorithm. The primers satisfied the criteria that melting temperature ( $\mathrm{Tm})$ was around $60 \sim 64^{\circ} \mathrm{C}$ and GC content was around $35 \sim 65 \%$. BLAST alignment was run to ensure the selected primers are unique to the desired target sequence. The genes and primer sequences can be found in Table 1 .

2.7. Western Blot. Total protein was extracted using a Total Protein Extraction Kit (Solarbio, Beijing, China). Proteins were separated on the $12 \%$ sodium dodecyl sulfatepolyacrylamide gel and then transferred to a polyvinylidene fluoride membrane. After blocking with 5\% milk in $1 \times$ Tween 20-phosphate-buffered saline (PBST), the membranes were incubated with specific primary antibodies against rat Nrf2 (Bioworld, 1:200), HO-1 (Abcam, 1:500), Caspase-3 (Abcam, 1:300) and cleaved Caspase-3 (CST, $1: 300$ ), and $\beta$-actin (TransGen, $1: 10000$ ) diluted in PBST overnight at $4^{\circ} \mathrm{C}$, followed by incubation with anti-rabbit IgG conjugated with HRP (TransGen) at a 1:2000 dilution (TransGen) or anti-mouse IgG conjugated with HRP (TransGen) at a 1:10000 dilution ( $\beta$-actin) for $1 \mathrm{~h}$ and then with Substrate Chemiluminescence Kit (Millipore, Billerica, MA, USA). Images were captured using the Alpha FluorChem E gel documentation system (ProteinSimple, USA).

2.8. Statistical Analysis. Data were expressed as (mean \pm SEM) and analyzed using SPSS 15.0 (SPSS Inc., Chicago, IL, USA). Normality and homogeneity of variances were evaluated prior to statistical analysis. Data were analyzed by oneway analysis of variance (ANOVA) and multiple comparisons were done between combined exposure groups and control and single-exposure groups by LSD when equal variances were assumed otherwise followed by Games-Howell. Differences were considered to be statistically significant at the probability level of $5 \%(P<0.05)$. 
TABLE 1: Primer sets used for quantitative real-time PCR.

\begin{tabular}{lccc}
\hline Gene name & Accession number & Forward primer & Reverse primer \\
\hline$\beta$-Actin & NM_031144.2 & 5-CTATCGGCAATGAGCGGTTCC-3 & 5-TGTGTTGGCATAGAGGTCTTTACG-3 \\
Nrf2 & NM_031789.2 & 5-ACGGTGGAGTTCAATGAC-3 & 5-TGTTGGCTGTGCTTTAGG-3 \\
HO-1 & NM_012580.2 & 5-GAAGAGGAGATAGAGCGAAAC-3 & 5-TGTGGCTGGTGTGTAAGG-3 \\
Caspase-3 & NM_012922.2 & 5-TGGAACGAACGGACCTGTG-3 & 5-CGGGTGCGGTAGAGTAAGC-3 \\
\hline
\end{tabular}

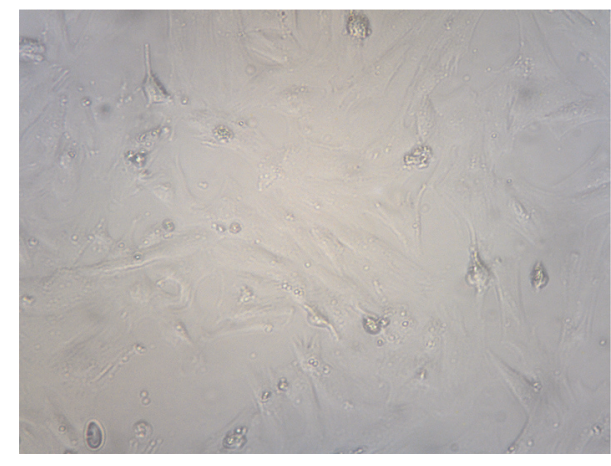

(a)

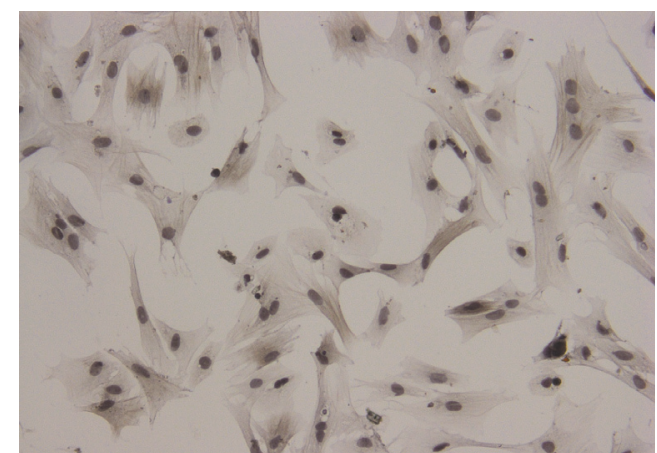

(b)

FIGURE 1: Morphology of Sertoli cells under inverted microscopy (a) and immunohistochemical staining of Sertoli cells with FSHR (b). After changing the medium, Sertoli cells showed tiny dendrites protruding and no germ cells were visible (a). Sertoli cells were positively stained brown with FSHR, and purity of Sertoli cells was $>95 \%$ (b). 200x magnification. Scale bars indicate $100 \mu \mathrm{m}$.

\section{Results and Discussion}

\subsection{Results}

3.1.1. Sertoli Cell Identification. As the germ cells mainly floated in the medium while Sertoli cells adhered to the flask, germ cells were removed after changing the medium after being cultured for 2 days. Sertoli cells showed transparent tiny dendrites protruding under microscope.

Sertoli cells are mainly activated and regulated by FSH to ensure the normal spermatogenesis in the adult, and this process is mainly mediated by the bonding of FSH and $\mathrm{FSH}$ receptor (FSHR), which is uniquely expressed in the membrane of Sertoli cells. Further identification was done by FSHR IHC staining (Figure 1(b)). All primary cells were positively stained brown with FSHR, indicating that they were Sertoli cells and purity of Sertoli cells is $>95 \%$. Sertoli cells morphology and IHC staining were shown in Figure 1.

3.1.2. Effects on Cell Proliferation Inhibition Rate. Cell proliferation inhibition rate at $24 \mathrm{~h}$ and $48 \mathrm{~h}$ is shown in Figure 2. Coexposure to genistein and MEHP at $1 \mu \mathrm{mol} / \mathrm{L}$ showed significant decrease compared with $\mathrm{M} 1(P<0.05)$. Exposure to $\mathrm{G}+\mathrm{M} 10$ and $\mathrm{G}+\mathrm{M} 100$ significantly decreased proliferation inhibition rate compared with corresponding MEHP single exposure $(P<0.05)$. Moreover, the calculated half-maximal inhibitory concentration (IC50) of MEHP at 24 and $48 \mathrm{~h}$ was $508.90 \mu \mathrm{M}$ and $154.28 \mu \mathrm{M}$, respectively, while the calculated IC50 of MEHP after genistein administration at 24 and $48 \mathrm{~h}$ was $826.60 \mu \mathrm{M}$ and $635.94 \mu \mathrm{M}$, respectively, manifesting that though not completely normalized, genistein may alleviate cell proliferative inhibition in prepubertal Sertoli cells development.

3.1.3. Effects on Cell Apoptosis and Necrosis. Effects of genistein, MEHP, and their combination on Sertoli cells apoptosis and necrosis are shown in Figure 3. The apoptosis rate analysis revealed significant increase in MEHP-treated groups compared with control $(P<0.05$ or $P<0.01)$. Coexposure to genistein and MEHP caused significant decrease compared with MEHP single exposure $(P<0.05)$, while increased apoptosis rate was still observed in G + M100 compared with control $(P<0.05)$. Similar trend was also found in the necrosis rate, which showed that M10 and M100 significantly increased the necrosis rate compared with control while the combination of $\mathrm{G}+\mathrm{M} 10$ and $\mathrm{G}+\mathrm{M} 100$ decreased necrosis rate compared with M10 or M100, manifesting that though not completely normalized, genistein may exert its protective role in prepubertal Sertoli cells development when exposed to MEHP.

3.1.4. Evaluation of ROS Production. ROS production after genistein, MEHP, and their combination exposure was shown in Figure 4. The cell permeable DCFH-DA is added to cells and is hydrolyzed by cellular esterases to DCFH. Once oxidized by ROS, DCFH becomes fluorescent DCF. We found that control and genistein exposure showed low ROS production, while exposure to MEHP at 1,10 , and $100 \mu \mathrm{mol} / \mathrm{L}$ caused significant increase of intracellular ROS production compared with control $(P<0.05$ or $P<0.01)$. The combined exposure of $\mathrm{G}+\mathrm{M1}, \mathrm{G}+\mathrm{M10}$, and $\mathrm{G}+\mathrm{M} 100$ showed decreased intracellular ROS level compared to corresponding MEHP single exposure $(P<0.05)$; however, significantly 

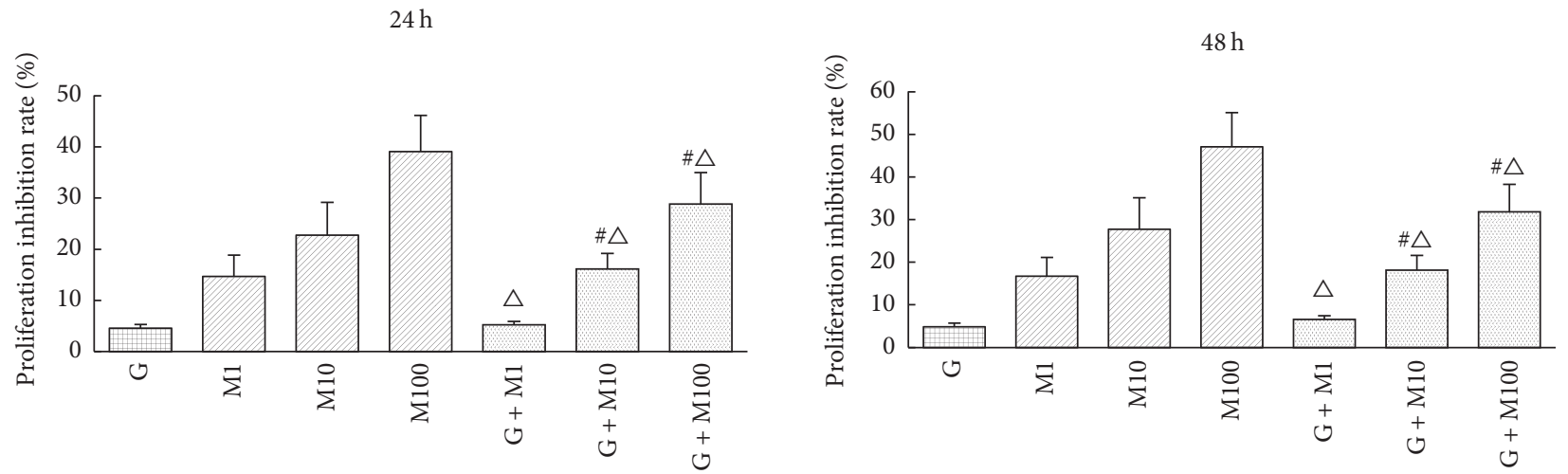

FIGURE 2: Effects of GEN and MEHP on Sertoli cells proliferation inhibition rate at $24 \mathrm{~h}$ and $48 \mathrm{~h}$. " Significantly different from G at $P<0.05$.

${ }^{\triangle}$ Significantly different from corresponding $\mathrm{M}$ at $P<0.05$.

higher ROS production was still observed compared with control or genistein group, which was consistent with changes of the proliferation inhibition rate as well as the apoptosis rate, indicating that genistein exerts it protection role by alleviating the ROS production in prepubertal Sertoli cells.

3.1.5. Effects on Medium Redox State. Medium redox state in each group at $48 \mathrm{~h}$ was shown in Figure 5. MEHP treatment resulted in significant reduction of medium T-AOC, SOD activity, and the ratio of GSH/GSSG, especially at the dose of $10 \mu \mathrm{m}$ and $100 \mu \mathrm{M}(P<0.05)$ while the combination of genistein and MEHP exhibited significant increase compared with corresponding single MEHP exposure $(P<0.05)$, showing opposite trends as the changes of intracellular ROS production, which indicates that the antioxidative role of genistein and the enhancement of Sertoli cells antioxidative ability may contribute to the decrease of ROS production. In contrast, TBARS level in M10, and 100 groups increased significantly compared with control $(P<0.05)$ while coadministration of genistein and MEHP showed significant decrease compared with corresponding single MEHP exposure $(P<0.05)$, which may critically depend on the increased antioxidative capacity after coadministration with genistein.

3.1.6. Gene Expression of Nrf2, HO-1, and Caspase-3. Gene expression analysis of Nrf2, HO-1, and Caspase- 3 of each group is shown in Figure 6. No significant changes were observed between control and Group G. Exposure to MEHP1 and 10 and $100 \mu \mathrm{M}$ caused significant decrease in Nrf2 and HO-1 expression compared with control $(P<0.05)$, while the combined exposure of genistein and MEHP showed increase in Nrf2 and HO-1 expression compared to corresponding MEHP single exposure $(P<0.05)$, which manifests that although oxidative stress was not completely attenuated, genistein may exert its protective role in prepubertal Sertoli cells via activating Nrf-2 and downstream HO-1. Caspase-3, the marker of cell apoptosis, showed significant increase in M1, M10, and M100 $(P<0.05)$, while the combination of genistein and MEHP decreased significantly compared with MEHP single exposure $(P<0.05)$, although upexpression was still observed compared with control.
3.1.7. Protein Expression of Nrf2, HO-1, Caspase-3, and Cleaved Caspase-3. Alterations of Nrf2, HO-1, and Caspase-3 mRNA were further validated at the protein level by western-blot and subsequent quantitative image analysis (Figure 7). Consistent with gene expression, protein expression of Nrf2 and HO1 showed similar trends. With the increase of MEHP doses, significant decrease in $\mathrm{Nrf} 2$ and $\mathrm{HO}-1$ expression relative to control was observed $(P<0.05)$, while the combination of $\mathrm{G}$ $+\mathrm{M} 1, \mathrm{G}+\mathrm{M10}$, and G + M100 showed increase in Nrf2 and HO-1 expression compared to corresponding MEHP single exposure $(P<0.05)$.

Caspase- 3 and its activated form of cleaved Caspase- 3 were elevated significantly in the three MEHP-treated groups $(P<0.05)$, while the combination with genistein significantly reduced cleaved Caspase- 3 expression although upexpression still existed compared with control $(P<0.05)$, which further indicates that genistein could partially attenuate Sertoli cell apoptosis in prepubertal testis, in which process Nrf- 2 and downstream HO-1 upregulation may play a vital role in alleviating MEHP-induced oxidative stress.

\section{Discussion}

The prepubertal testis has classically been defined as a quiescent organ, but recent findings revealed that prepuberty is a critical window for male reproductive system development; during this stage the process of testicular spermatogenesis and steroidogenesis is highly responsive to EDCs [19], finally resulting in disturbed spermatogenesis and higher incidence of testicular germ cell cancer [20]. During the fetal and neonatal period, Sertoli cells keep intensively proliferating until postnatal day 15 in rats and then Sertoli cells go into relatively quiescent prepubertal stage [21]. Any disturbance that interferes with Sertoli cells maturation leading to functional impairment and decrease of cell number would detrimentally deteriorate testicular function and the spermatogenic potential in the adult [22]. However, the relative scarcity of studies on this stage and the imminent concern on EDCs mixture exposure make it urgent to investigate the possible acute effects on testis cells development and other reproductive parameters [19]. 

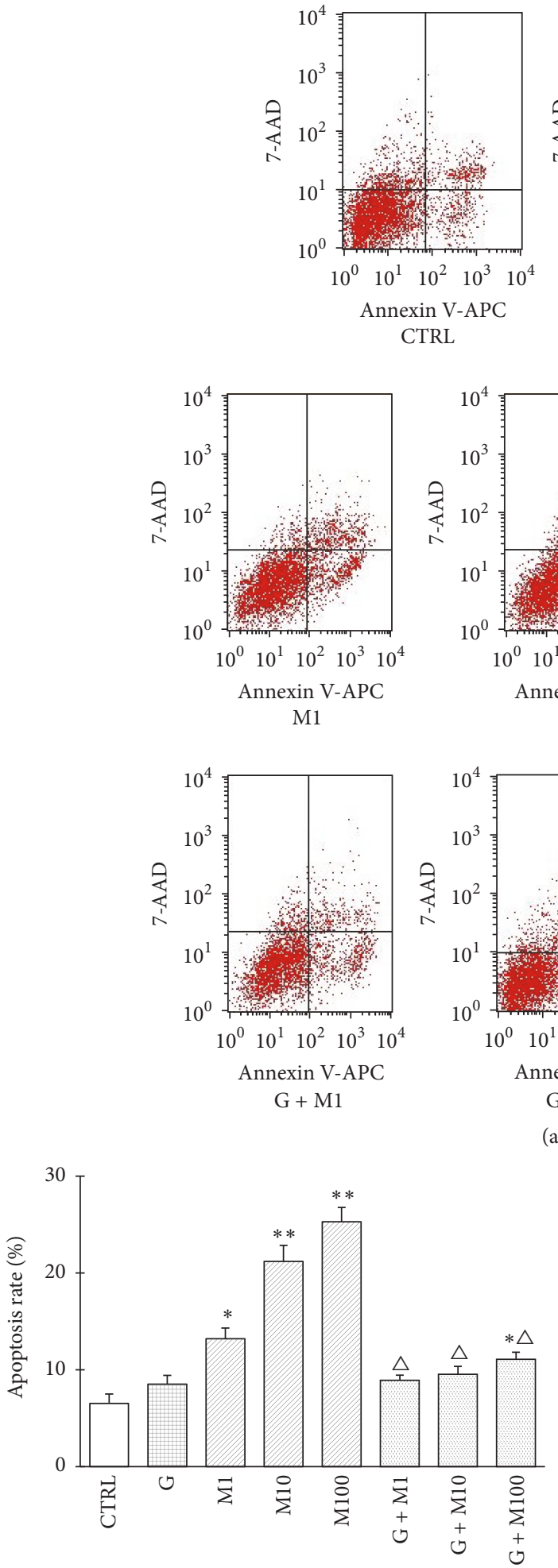

(a)

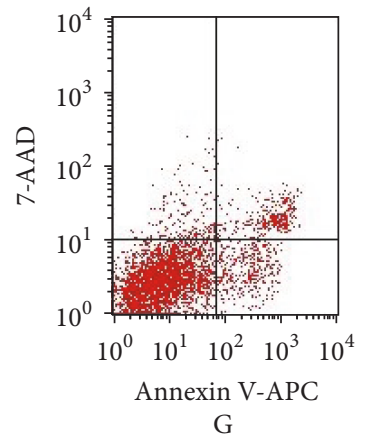

G
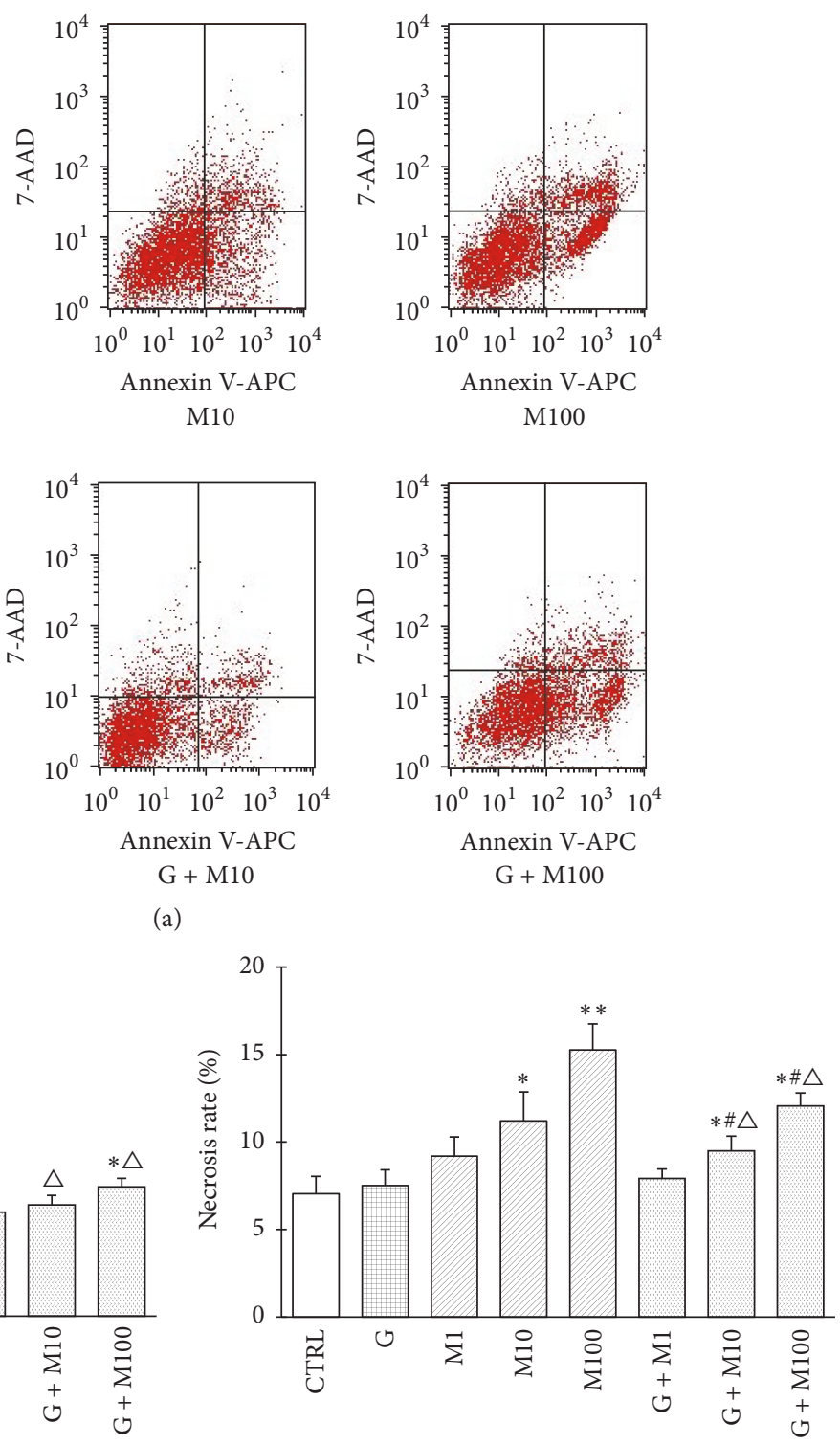

(b)

FIGURE 3: Effects of GEN and MEHP exposure on Sertoli cell apoptosis and necrosis. After being treated for $48 \mathrm{~h}$, Sertoli cells were collected for Annexin V-APC and 7-AAD staining followed by flow cytometry analysis. (a) shows flow cytometric plots. (b) shows flow cytometric analysis result. * Significantly different from control at $P<0.05$. ${ }^{* *}$ Significantly different from control at $P<0.01 .{ }^{*}$ Significantly different from $\mathrm{G}$ at $P<0.05 .{ }^{\triangle}$ Significantly different from corresponding $\mathrm{M}$ at $P<0.05$. 

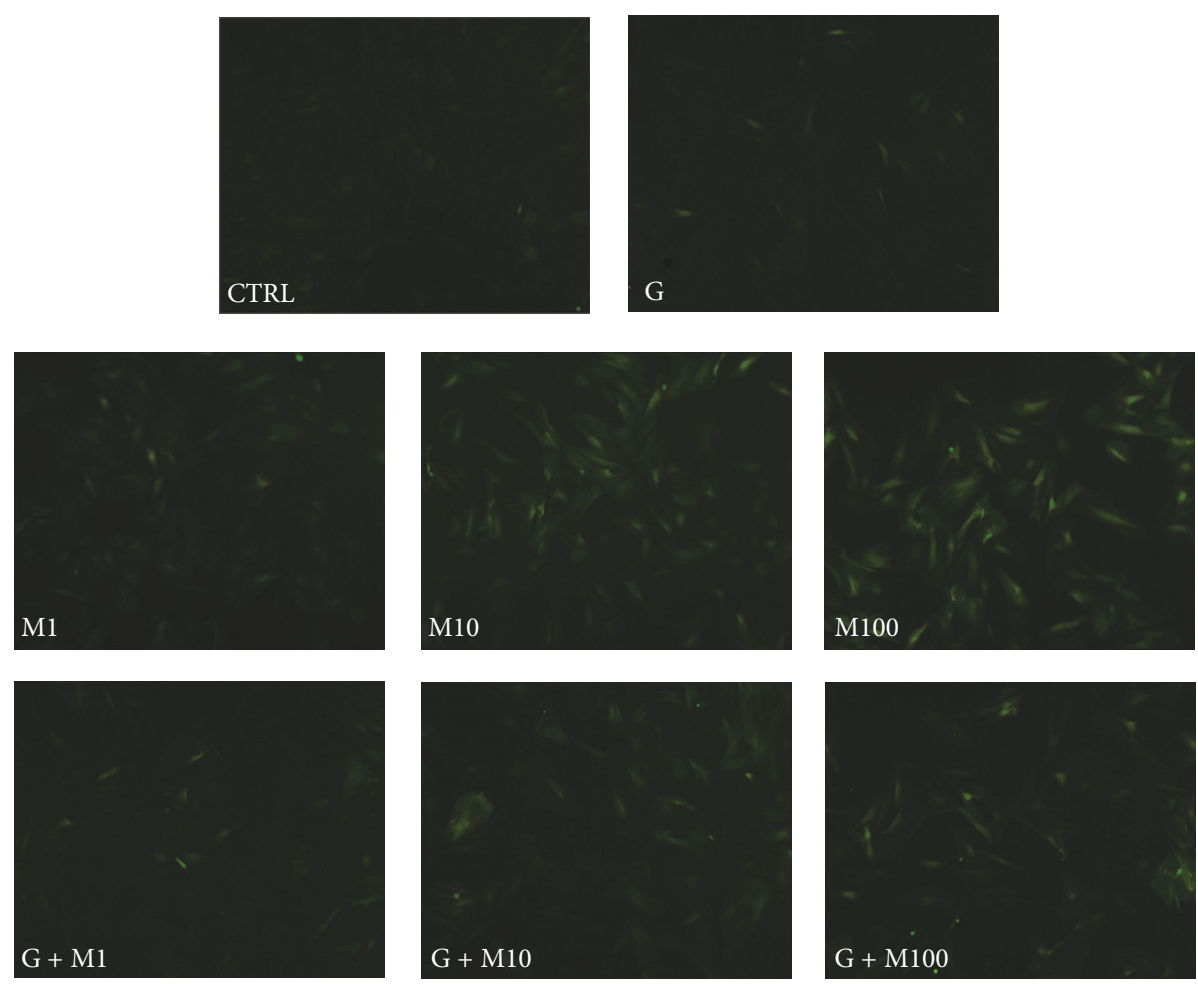

(a)

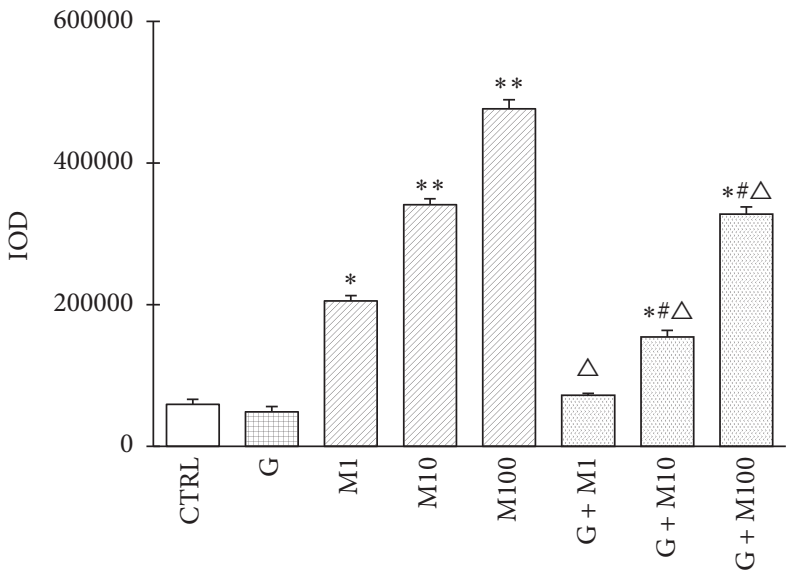

(b)

FIgURE 4: Effects of GEN and MEHP exposure on Sertoli cells ROS production. After being treated for $48 \mathrm{~h}$, Sertoli cells were collected for DCFH-DA staining. (a) shows fluorescence images. (b) shows fluorescence analysis result. IOD $=$ area $\times$ average density. ${ }^{*}$ Significantly different from control at $P<0.05 ;{ }^{* *}$ significantly different from control at $P<0.01$; ${ }^{\#}$ significantly different from $\mathrm{G}$ at $P<0.05$; and ${ }^{\triangle}$ significantly different from corresponding $\mathrm{M}$ at $P<0.05$.

The present study showed that single exposure to MEHP, especially at high doses, induced elevated prepubertal Sertoli cells proliferation inhibition rate as well as the apoptosis rate, accompanied by increased intracellular oxidative stress and disturbed antioxidative enzymes activities. For peripubertal animals, MEHP was confirmed to disrupt Sertoli cells cytoskeleton and tight junctions followed by increased apoptosis and detachment from germ cells, in which process Sertoli cells number would limit germ cell population [11]. Compared to adult, peripubertal rodents are particularly sensitive to phthalate-induced testicular injury. The mechanism that MEHP-induced testis toxicity includes decreased Sertoli cell number and impaired cell function, which may detrimentally affect the first wave of spermatogenesis starting around prepuberty [23]. In vivo study showed that MEHP administration led to loss of communicating interactions between Sertoli cells and germ cells in the rats [24]. In the in vitro study using rat testis organotypic culture model, MEHP at $10 \mu \mathrm{M}$ caused decreased Sertoli cell proliferation [25] and MEHP at $100 \mu \mathrm{M}$ disrupted Sertoli cell maturity in 

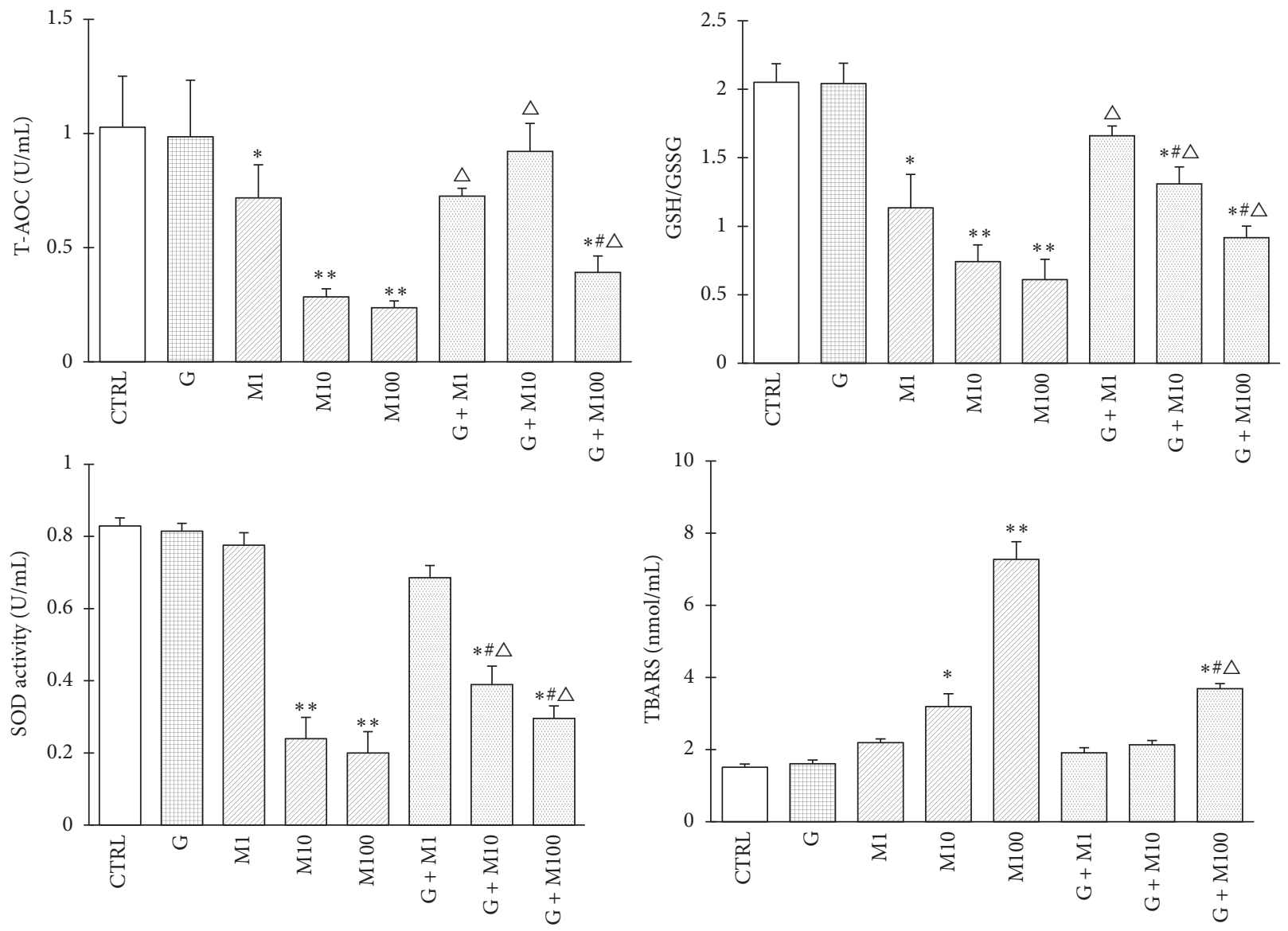

FIGURE 5: Effects of GEN and MEHP exposure on medium redox state. ${ }^{*}$ Significantly different from control at $P<0.05$, ${ }^{* *}$ significantly different from control at $P<0.01$; ${ }^{*}$ significantly different from $\mathrm{G}$ at $P<0.05 ;{ }^{\triangle}$ significantly different from corresponding $\mathrm{M}$ at $P<0.05$.

neonatal rat testis cultures [26]. In our in vivo study focusing on prepubertal rats exposed to GEN and DEHP, we also found Sertoli cells were the main target of phthalates toxicity, of which the most significant histological abnormality we found was the tubular vacuolation, indicative of a breakdown in Sertoli-germ cell junctions [27]. Since Sertoli cells are capable of supporting a finite number of germ cells through cell-cell contact and maintaining the integrity of the epithelium, the decreased Sertoli cell number and functional deterioration established during prepuberty will inevitably lead to interruption in the differentiation of germinal cells or even the spermatogenesis arrest. Interestingly, the combined exposure to genistein and MEHP showed significant decrease in cell proliferation inhibition rate, apoptosis rate, and oxidative stress markers compared with MEHP single exposure. It is reasonable to speculate that genistein may exert protective role in its combination with MEHP, which acts in the way different from their classical dose-responsive way, highlighting the importance of assessing impacts across a range of doses, ages, and mixtures.

Redox control of testicular cell physiology is one of the most important regulatory mechanisms. In normal physiological state, potent antioxidant system protects testicular cells against ROS damage, but EDCs exposure could probably cause imbalance in prooxidant/antioxidant content and result in oxidative injuries [28]. DEHP and MEHP have been proven to have deleterious effects on the male reproductive system via inducing dramatic changes in germ cells, Sertoli cells, and Leydig cells [11, 29, 30]. However, the underlying mechanism by which MEHP exerts toxic effects on reproductive system has not yet been fully elucidated. Our results showed that exposure to consecutive three doses of MEHP caused impairment of antioxidative enzyme activities, alternation of the ratio of GSH/GSSG, and the increase of TBARS. The medium antioxidative enzymes activities were closely related to the dose of MEHP, which showed aggravation of oxidative stress as the doses increase. Culty et al. [10] reported peroxisome proliferatoractivated receptors (PPARs) activation played a key role in suppressing fetal testosterone biosynthesis after phthalates exposure, but more recently oxidative stress was found to medicate phthalates induced testicular dysfunction, in which process enzymatic and nonenzymatic cellular antioxidants were disturbed accompanied by elevated level of reactive oxygen species production and DNA damage [31]. Kasahara et al. [32] found that DEHP enhanced the generation of ROS and selectively decreased GSH and ascorbic acid in the testis, thereby inducing apoptosis of spermatocytes to cause atrophy of testis. In the study conducted to exam sperm function in adult rats after low-dose exposure to DEHP 

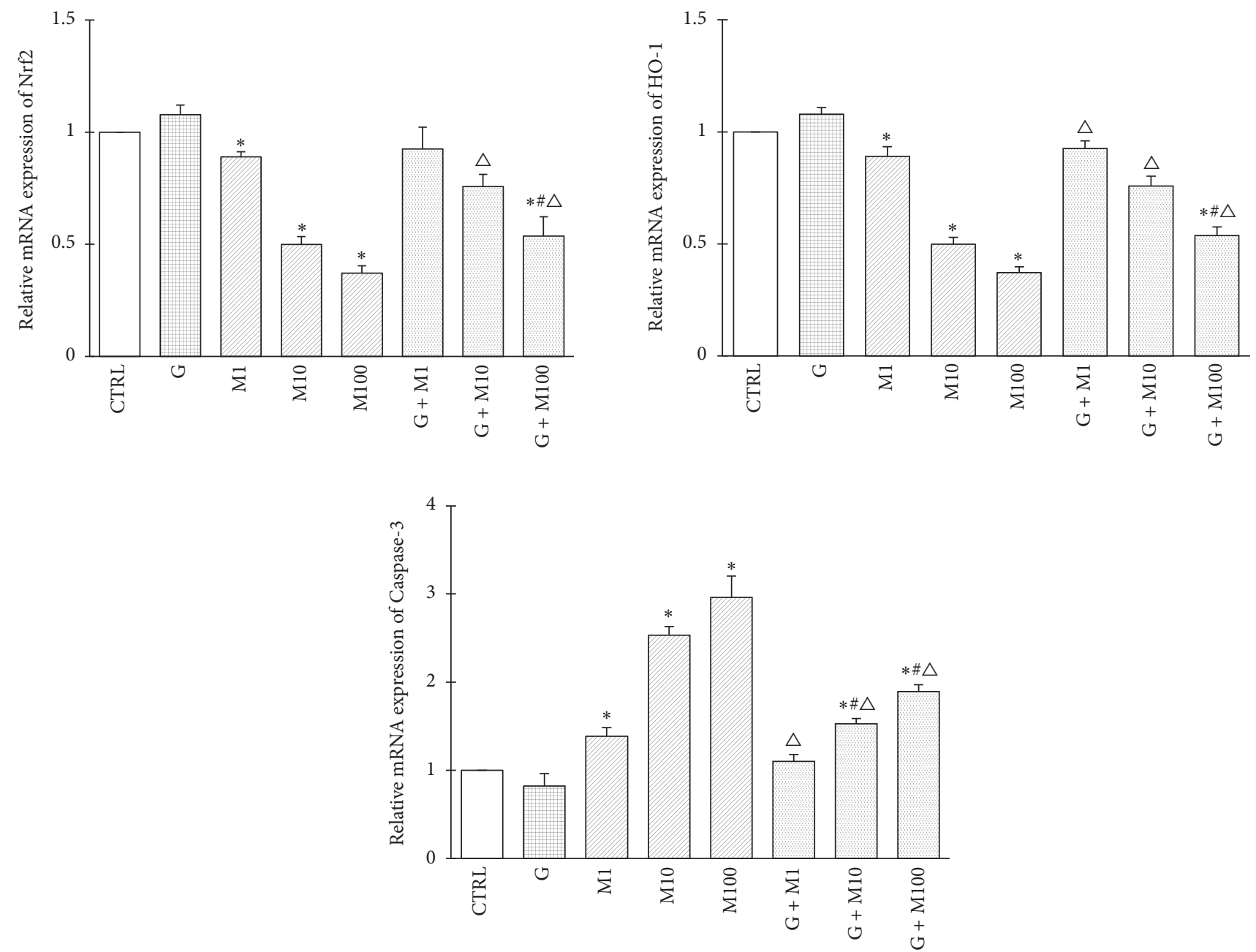

Figure 6: Effects of GEN and MEHP exposure on gene expression of Nrf2, HO-1, and Caspase-3. * Significantly different from control at $P<0.05$; ${ }^{*}$ significantly different from $\mathrm{G}$ at $P<0.05 ;{ }^{\triangle}$ significantly different from corresponding $\mathrm{M}$ at $P<0.05$.

during adolescence, Hsu et al. [33] found significant increase of hydrogen peroxide $\left(\mathrm{H}_{2} \mathrm{O}_{2}\right)$ generation in the sperm of the $1000 \mu \mathrm{g} / \mathrm{kg}$ DEHP-treated group, accompanied by higher percentage of sperm with tail abnormality and sperm DNA fragmentation index.

For combined exposures, the mixtures may act not simply in adding or subtracting manners of individual components [15]. The combined exposure of genistein and MEHP showed upregulated antioxidative enzymes activities and downregulated TBARS production compared with DEHP-single exposure. Even though genistein seems to help testis recover form MEHP-induced Sertoli cell injuries, the combined exposure of G + M10 and G + M100, however, still showed downregulated enzymes activities and increase of TBARS level compared to control, suggesting that genistein exposure could partially attenuate MEHP-induced acute alterations in prepubertal Sertoli cells by enhancing cellular antioxidative ability. Genistein is believed to have both estrogenic [5] and antioxidative effects [34]. Recent study revealed that genistein could improve T-AOC while decreasing protein carbonyl and TBARS levels in genistein-treated nephrotic rats [35], and similar findings were also reported in the other in vitro and in vivo studies $[36,37]$. Although there were combined studies of genistein with other EDCs in early researches, the study on the combination of MEHP and genistein has been lacking. Our most recent study (collaborating with Martine Culty's group) examined testicular effects after gestational exposure to DEHP at relatively low dose and revealed that the redox markers (Nqo1, Sod2, Sod3, Trx, Gst, and Cat) were significantly altered at PND3, while being attenuated when combined with GEN, suggesting the involvement of cellular stress in short-term DEHP effects and a protective effect of GEN [13].

We further investigated the expression of genes and proteins involved in the process of cell antioxidative defence and apoptosis. The present study showed that single exposure to MEHP, especially at high doses, induced the downregulation of Nrf2 and HO-1 expression while caspase-3 was found to be upregulated. By contrast, cotreatment with genistein attenuated these effects. In the event of oxidative stress, stresssensing cysteine in cytoplasmic KEAP1 changes the conformation and subsequently dissociates with $\mathrm{Nrf} 2$, followed by Nrf2 migration to the nucleus where it heterodimerizes with small Maf protein and binds to ARE, eventually resulting 

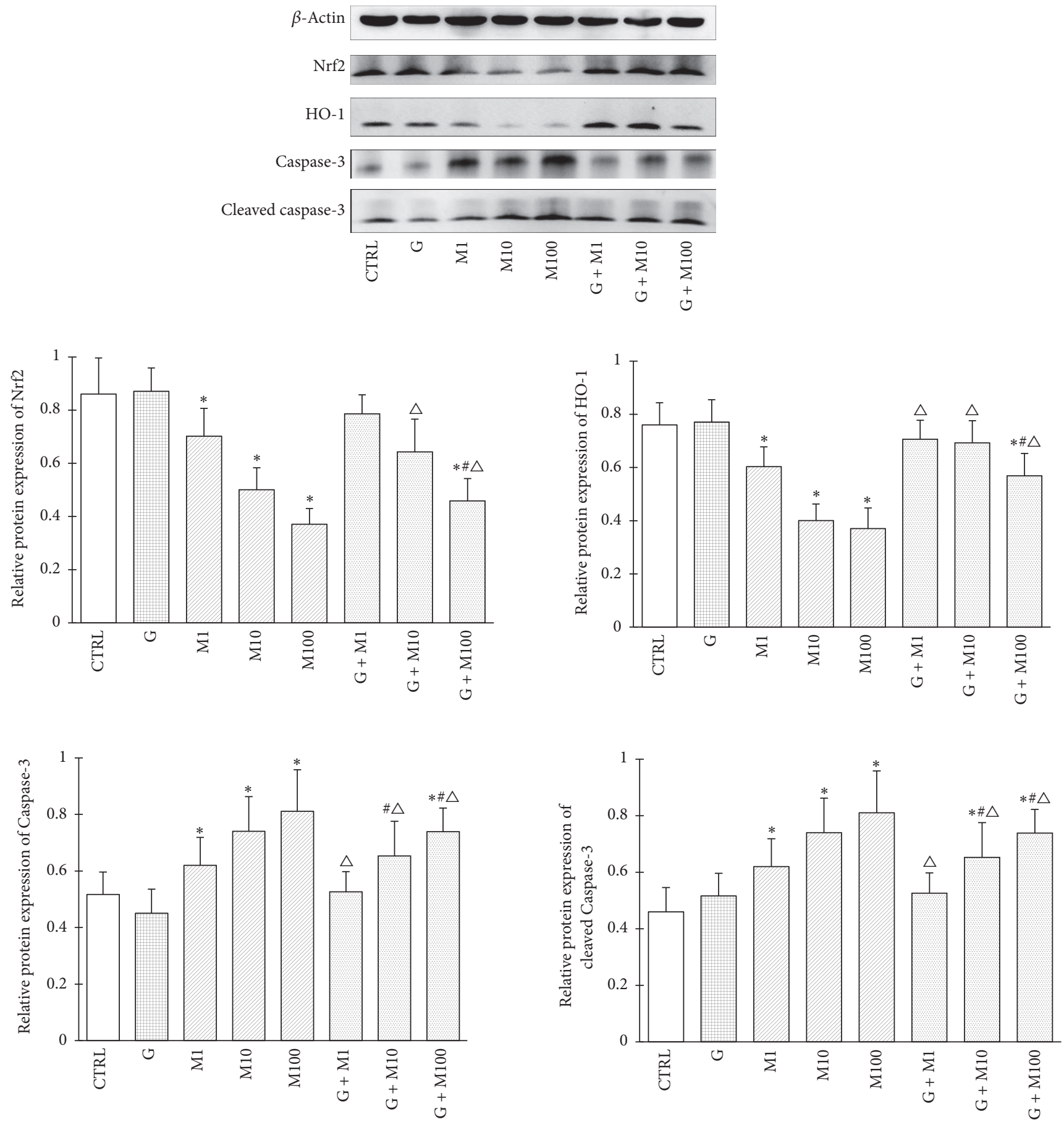

FiguRE 7: Effects of GEN and MEHP exposure on protein expression of Nrf2, HO-1, Caspase-3, and cleaved Caspase-3. * Significantly different from control at $P<0.05{ }^{\#}$ significantly different from $\mathrm{G}$ at $P<0.05$; and ${ }^{\triangle}$ significantly different from corresponding $\mathrm{M}$ at $P<0.05$.

in the transcriptional regulation of target genes [38]. Of all the target genes, HO-1 has been reported to be observed exclusively in the Sertoli cells in rats and play a role in normal spermatogenesis [39]. Different from the other isomers including $\mathrm{HO}-2$ or $\mathrm{HO}-3, \mathrm{HO}-1$ is an inducible type of $\mathrm{HO}$ and detectable under normal condition. Moreover, HO-1 is believed to have the most AREs on its promoter, making it highly protective by degrading its prooxidant substrate, heme, and enhancing the antioxidants biliverdin and bilirubin production. Our results suggest that genistein functions as an antioxidant in the testes and suppresses apoptosis by acting as scavengers of ROS via activating Nrf2 and $\mathrm{HO}-1$, exerting protection against MEHP-induced Sertoli cell toxicity, which is consistent with the morphological and histological changes in our in vivo study. Moreover, assessing reproductive risk based on single chemical effect might not 
faithfully represent the true outcome of mixture exposure during critical periods of male reproductive development. Future experiments will involve detailed analysis of cellular and molecular events contributing to acute as well as chronic effects in testis development including epigenetic aberrations that may exert long-term perturbations in gene expression.

\section{Conclusions}

In this study, our results revealed that MEHP could disrupt prepubertal Sertoli cells proliferation by increasing intracellular ROS level especially at high doses. However, coadministration of genistein could partially alleviate MEHP-induced prepubertal Sertoli cells damage via enhancement of testicular antioxidative enzymes activities and upregulation of $\mathrm{Nrf} 2$ and HO-1. Cotreatment of genistein devoid of endocrinedisrupting side effects may have promising future on its curative role for attenuating other EDCs-induced reproductive disorders. Based on the results, it can be speculated that dietary intake of isoflavones may make the prepubertal testes less susceptible to phthalates induced injury.

\section{Conflicts of Interest}

The authors declare that they have no conflicts of interest.

\section{Acknowledgments}

The authors appreciate Dr. Jun Zhao (Department of Urology, The Second Affiliated Hospital, Xi'an Jiaotong University) for assistance and various suggestions with respect to the animal model. They thank Dr. Martine Culty (Research Institute of McGill University Health Center, McGill University, now at Department of Pharmacology and Pharmaceutical Sciences, School of Pharmacy, University of South California) for her critical helpful experimental suggestions. The authors also thank Dr. Yong-Wei Huo (Department of Anatomy and Histoembryology, Medicine School of Xi'an Jiaotong University) for her kind technical support. This work was partially supported by National Natural Science Foundation of China (Grant no. 81272846).

\section{References}

[1] A. S. Nassouri, F. Archambeaud, and R. Desailloud, "Endocrine disruptors: echoes of congress of Endocrinology in 2012," Annales d'Endocrinologie, vol. 73, supplement 1, pp. S36-S44, 2012.

[2] J. Chen, K. S. Saili, Y. Liu et al., "Developmental bisphenol A exposure impairs sperm function and reproduction in zebrafish," Chemosphere, vol. 169, pp. 262-270, 2017.

[3] X.-Z. Wang, S.-S. Liu, Y. Sun, J.-Y. Wu, Y.-L. Zhou, and J.-H. Zhang, "Beta-cypermethrin impairs reproductive function in male mice by inducing oxidative stress," Theriogenology, vol. 72, no. 5, pp. 599-611, 2009.

[4] I. Sidorkiewicz, K. Zaręba, S. Wołczyński, and J. Czerniecki, "Endocrine-disrupting chemicals-Mechanisms of action on male reproductive system," Toxicology \& Industrial Health, vol. 33, no. 7, pp. 601-609, 2017.
[5] C. R. Cederroth, J. Auger, C. Zimmermann, F. Eustache, and S. Nef, "Soy, phyto-oestrogens and male reproductive function: a review," International Journal of Andrology, vol. 33, no. 2, pp. 304-316, 2010.

[6] L. Zhao, Y. Wang, J. Liu et al., "Protective effects of genistein and puerarin against chronic alcohol-induced liver injury in mice via antioxidant, anti-inflammatory, and anti-apoptotic mechanisms," Journal of Agricultural and Food Chemistry, vol. 64, no. 38, pp. 7291-7297, 2016.

[7] J. Kumi-Diaka, V. Nguyen, and A. Butler, "Cytotoxic potential of the phytochemical genistein isoflavone (4,5,7-trihydroxyisoflavone) and certain environmental chemical compounds on testicular cells," Biology of the Cell, vol. 91, no. 7, pp. 515-523, 1999.

[8] D. K. Gong, B. H. Liu, and X. H. Tan, "Genistein prevents cadmium-induced neurotoxic effects through its antioxidant mechanisms," Drug Research, 2014.

[9] S. R. Georgetti, R. Casagrande, F. T. M. C. Vicentini, M. M. Baracat, W. A. Verri Jr., and M. J. V. Fonseca, "Protective effect of fermented soybean dried extracts against TPA-induced oxidative stress in hairless mice skin," BioMed Research International, vol. 2013, Article ID 340626, 8 pages, 2013.

[10] M. Culty, R. Thuillier, W. Li et al., "In utero exposure to di-(2-ethylhexyl) phthalate exerts both short-term and longlasting suppressive effects on testosterone production in the rat," Biology of Reproduction, vol. 78, no. 6, pp. 1018-1028, 2008.

[11] C. M. Sobarzo, N. D. M. Rosana, L. Livia, D. Berta, and H. F. Schteingart, "Mono-(2-ethylhexyl) phthalate (MEHP) affects intercellular junctions of Sertoli cell: A potential role of oxidative stress," Reproductive Toxicology, vol. 58, pp. 203-212, 2015.

[12] S. Kim, S. Kang, G. Lee et al., "Urinary phthalate metabolites among elementary school children of Korea: sources, risks, and their association with oxidative stress marker," Science of the Total Environment, vol. 472, pp. 49-55, 2014.

[13] S. Jones, A. Boisvert, S. Francois, L. Zhang, and M. Culty, "In utero exposure to di-(2-ethylhexyl) phthalate induces testicular effects in neonatal rats that are antagonized by genistein cotreatment," Biology of Reproduction, vol. 93, no. 4, article no. 92, 2015.

[14] R. P. Grinspon and R. A. Rey, "Anti-müllerian hormone and sertoli cell function in paediatric male hypogonadism," Hormone Research in Paediatrics, vol. 73, no. 2, pp. 81-92, 2010.

[15] I. Silins and J. Högberg, "Combined toxic exposures and human health: biomarkers of exposure and effect," International Journal of Environmental Research and Public Health, vol. 8, no. 3, pp. 629-647, 2011.

[16] W. Wang, M. Xu, and S. Zhang, "The modified isolation and culture method of rat Sertoli cells," Sichuan Da Xue Xue Bao Yi Xue Ban, vol. 34, no. 4, pp. 736-737, 2003.

[17] V. Muczynski, J. P. Cravedi, A. Lehraiki et al., "Effect of mono-(2-ethylhexyl) phthalate on human and mouse fetal testis: In vitro and in vivo approaches," Toxicology and Applied Pharmacology, vol. 261, no. 1, pp. 97-104, 2012.

[18] Y. Cao, A. M. Calafat, D. R. Doerge et al., "Isoflavones in urine, saliva, and blood of infants: Data from a pilot study on the estrogenic activity of soy formula," Journal of Exposure Science and Environmental Epidemiology, vol. 19, no. 2, pp. 223-234, 2009.

[19] J. E. Perobelli, “The male peripubertal phase as a developmental window for reproductive toxicology studies," Current Pharmaceutical Design, vol. 20, no. 34, pp. 5398-5415, 2014. 
[20] N. E. Skakkebaek, E. Rajpert-De Meyts, G. M. Buck Louis et al., "Male reproductive disorders and fertility trends: Influences of environment and genetic susceptibility," Physiological Reviews, vol. 96, no. 1, pp. 55-97, 2015.

[21] S. Schlatt and J. Ehmcke, "Regulation of spermatogenesis: an evolutionary biologist's perspective," Seminars in Cell \& Developmental Biology, vol. 29, no. 1, pp. 2-16, 2014.

[22] L. Johnson, D. L. Thompson Jr., and D. D. Varner, "Role of Sertoli cell number and function on regulation of spermatogenesis," Animal Reproduction Science, vol. 105, no. 1-2, pp. 23-51, 2008.

[23] C. J. Murphy, A. R. Stermer, and J. H. Richburg, "Age- and species-dependent infiltration of macrophages into the testis of rats and mice exposed to mono-(2-ethylhexyl) phthalate (MEHP)," Biology of Reproduction, vol. 91, no. 1, article no. 18, 2014.

[24] E. Kleymenova, C. Swanson, K. Boekelheide, and K. W. Gaido, "Exposure in utero to di(n-butyl) phthalate alters the vimentin cytoskeleton of fetal rat sertoli cells and disrupts sertoli cellgonocyte contact," Biology of Reproduction, vol. 73, no. 3, pp. 482-490, 2005.

[25] F. Chauvigné, A. Menuet, L. Lesné et al., "Time- and doserelated effects of di-(2-ethylhexyl) phthalate and its main metabolites on the function of the rat retal testis in vitro," Environmental Health Perspectives, vol. 117, no. 4, pp. 515-521, 2009.

[26] A. Lehraiki, C. Racine, A. Krust, R. Habert, and C. Levacher, "Phthalates impair germ cell number in the mouse fetal testis by an androgen- and estrogen-independent mechanism," Toxicological Sciences, vol. 111, no. 2, pp. 372-382, 2009.

[27] B.-G. Xie, J. Li, and W.-J. Zhu, "Pathological changes of testicular tissue in normal adult mice: A retrospective analysis," Experimental and Therapeutic Medicine, vol. 7, no. 3, pp. 654656, 2014.

[28] H.-J. Wu, C. Liu, W.-X. Duan et al., "Melatonin ameliorates bisphenol A-induced DNA damage in the germ cells of adult male rats," Mutation Research - Genetic Toxicology and Environmental Mutagenesis, vol. 752, no. 1-2, pp. 57-67, 2013.

[29] S. Jones, A. Boisvert, and TB. Duong, "Disruption of Rat Testis Development Following Combined In," BIOL REPROD, 2014.

[30] L.-D. Zhang, Q. Deng, Z.-M. Wang et al., "Disruption of reproductive development in male rat offspring following gestational and lactational exposure to di-(2-ethylhexyl) phthalate and genistein," Biological Research, vol. 46, no. 2, pp. 139-146, 2013.

[31] P. Erkekoglu, W. Rachidi, O. G. Yuzugullu et al., "Evaluation of cytotoxicity and oxidative DNA damaging effects of di(2-ethylhexyl)-phthalate (DEHP) and mono(2-ethylhexyl)phthalate (MEHP) on MA-10 Leydig cells and protection by selenium," Toxicol Appl Pharmacol, vol. 248, no. 1, pp. 52-62, 2010.

[32] E. Kasahara, E. F. Sato, M. Miyoshi et al., "Role of oxidative stress in germ cell apoptosis induced by di(2-ethylhexyl)phthalate," Biochemical Journal, vol. 365, no. 3, pp. 849-856, 2002.

[33] P. Hsu, Y. Kuo, Y. Leon Guo et al., "The adverse effects of low-dose exposure to $\mathrm{Di}$ (2-ethylhexyl) phthalate during adolescence on sperm function in adult rats," Environmental Toxicology, vol. 31, no. 6, pp. 706-712, 2016.

[34] Y. Qian, T. Guan, M. Huang et al., "Neuroprotection by the soy isoflavone, genistein, via inhibition of mitochondria-dependent apoptosis pathways and reactive oxygen induced-NF- $\kappa \mathrm{B}$ activation in a cerebral ischemia mouse model," Neurochemistry International, vol. 60, no. 8, pp. 759-767, 2012.
[35] M. H. Javanbakht, R. Sadria, and M. Djalali, "Soy protein and genistein improves renal antioxidant status in experimental nephrotic syndrome," Nefrología, vol. 34, no. 4, pp. 483-490, 2014.

[36] W. Y. Boadi and D. Johnson, "Effects of low doses of quercetin and genistein on oxidation and carbonylation in hemoglobin and myoglobin," Journal of Dietary Supplements, vol. 11, no. 3, pp. 272-287, 2014.

[37] W. Banz, S. Hauck, B. Gename, T. Winters, and A. Bartke, "Soy isoflavones modify liver free radical scavenger systems and liver parameters in Sprague-Dawley rats," Journal of Medicinal Food, vol. 7, no. 4, pp. 477-481, 2004.

[38] M. C. Lu, J. A. Ji, Z. Y. Jiang, and Q. D. You, "The Keap1-Nrf2ARE pathway as a potential preventive and therapeutic target: an update," Medicinal Research Reviews, vol. 36, no. 5, pp. 924963, 2016.

[39] M. D. Maines and J. F. Ewing, "Stress response of the rat testis: In situ hybridization and immunohistochemical analysis of heme oxygenase-1 (HSP32) induction by hyperthermia," Biology of Reproduction, vol. 54, no. 5, pp. 1070-1079, 1996. 


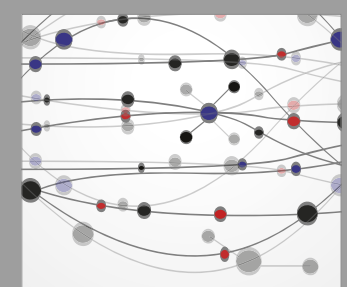

The Scientific World Journal
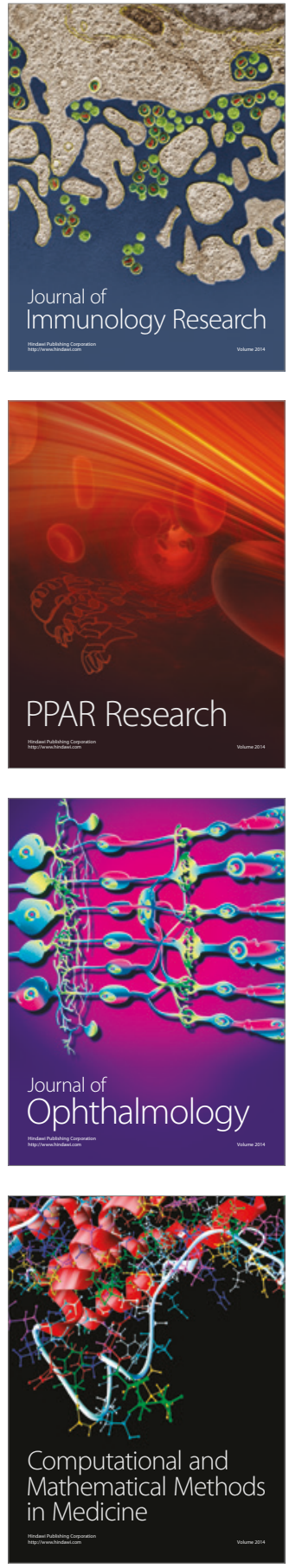

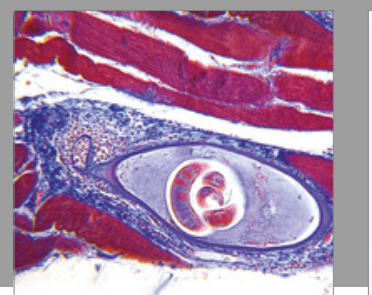

Gastroenterology Research and Practice
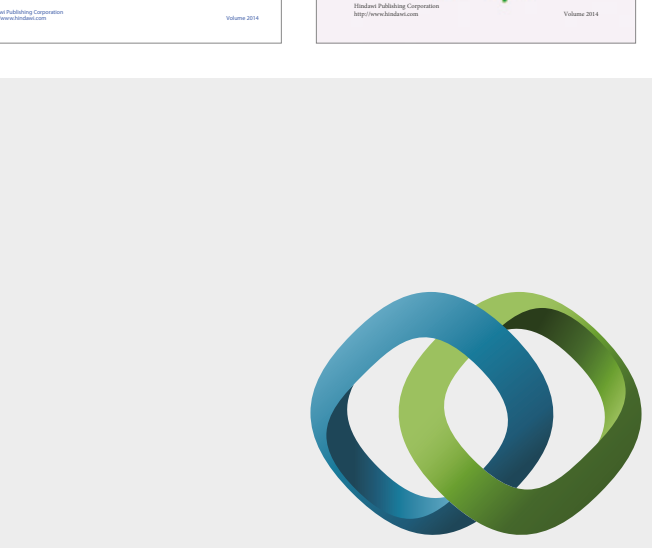

\section{Hindawi}

Submit your manuscripts at

https://www.hindawi.com
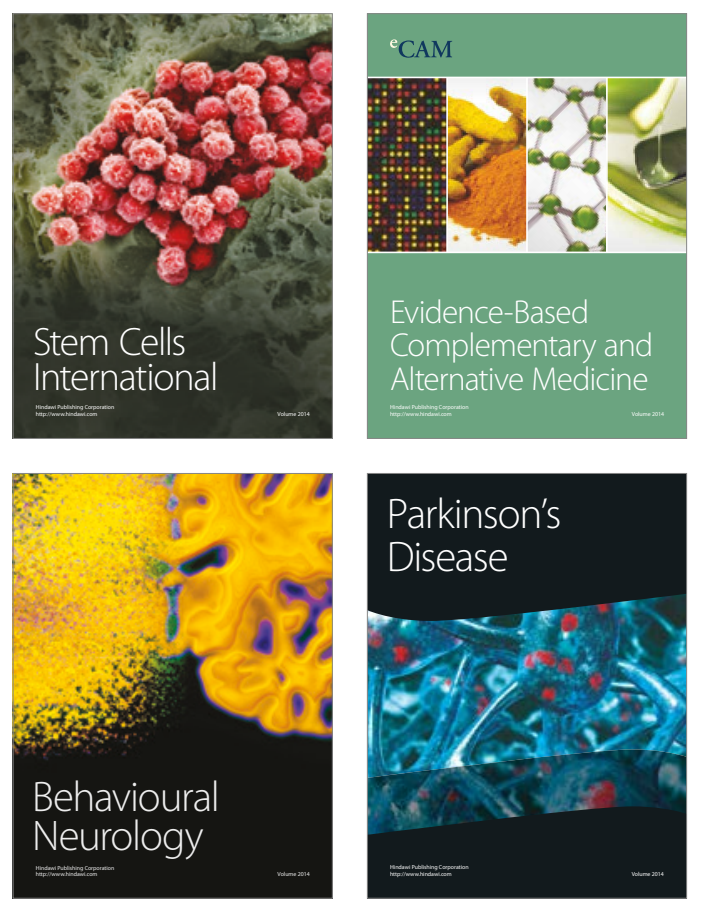
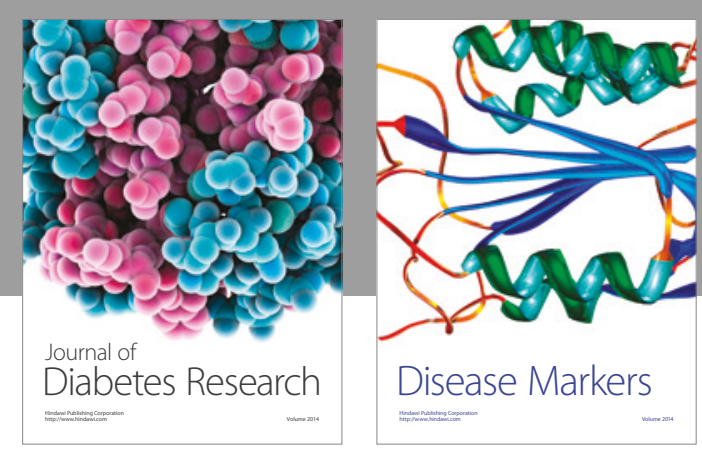

Disease Markers
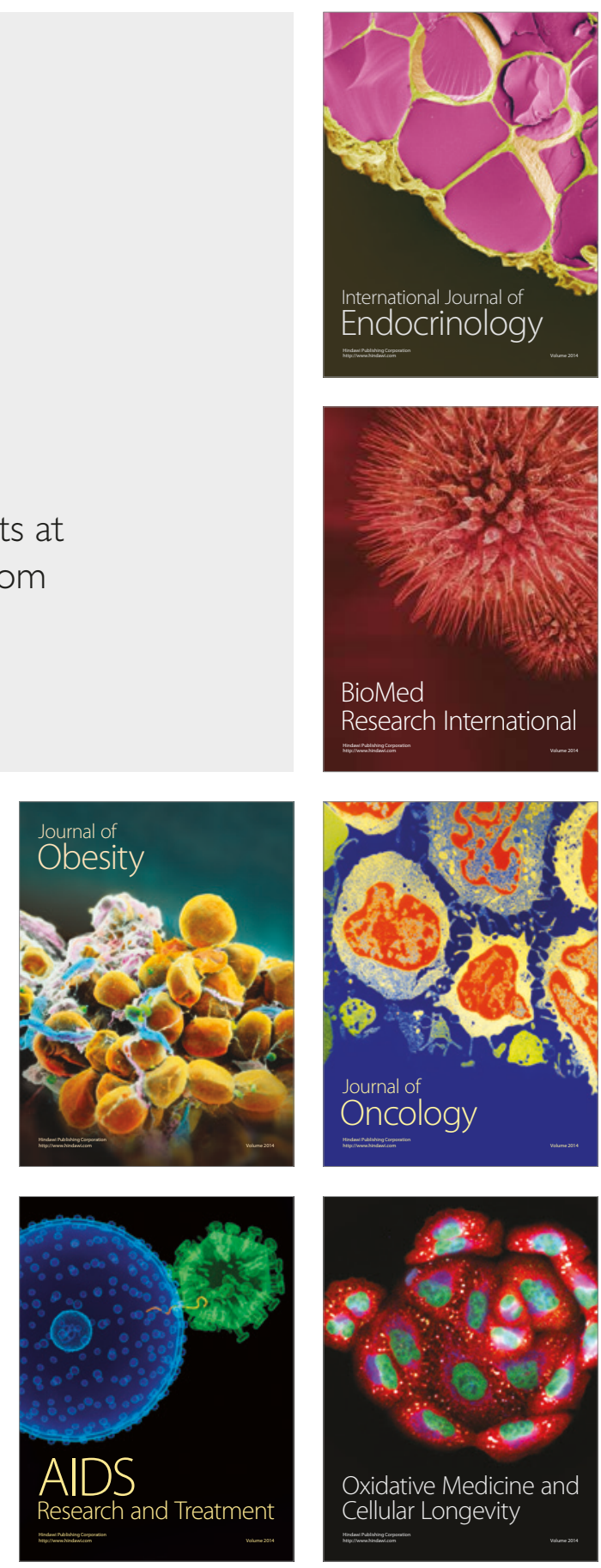